\title{
In memory of Dr. Henry T. Lynch
}

The worldwide oncology community and all patients subject to hereditable cancers lost a great friend and colleague in early June, 2019. Henry Lynch was literally and figuratively a towering figure, but also a kind and humble man who saw the greatest good in helping to identify and prevent malignancies. I am honored to write this piece in memory of Henry, as I had the great luck of knowing him personally. I saw him last in the Fall of 2017, when he and I were honored by Georgetown University for our work in gastrointestinal cancers. He was wheelchair-bound at the time, but was nevertheless the center of the room, clearly enjoying the evening. I also remember lecturing together with him at a symposium in Belfast, Northern Ireland, some years back. His lectures were, as always, masterly, with great clarity and precision. Each evening, after dinner, he and his wife Jane would join the younger faculty for a pub crawl, and both kept up admirably. Finally, he and his wife contributed a chapter on cancer genetics to the 3rd edition of the Oxford Textbook of Oncology, which I edited 5 years ago. At some point, I heard from Oxford Press that his chapter would be a bit late, as he related to them that his wife had passed away in the midst of writing. I wrote him a letter of condolence, to which he replied "God bless you, Dan".

Henry Lynch died on June 2 at Bergan Mercy Hospital, the main teaching hospital for Creighton University in Omaha, where he had spent most of his career. He was 91 . He was a child of the depression, and left high school to join the army in WW II, using a cousin's name so he could enlist at age 15. He was a large man, and became a professional boxer under the name "Hammerin' Hank". After receiving a high school equivalency, he enrolled at the University of Oklahoma. He graduated in 1951, and subsequently received a master's degree in clinical psychology from the University of Denver.

He earned his medical degree at the University of Texas Medical Branch in Galveston in 1960, after also completing all the coursework toward a Ph.D. in human genetics at Austin. He was hired by Creighton University in Omaha, Nebraska, in 1967, and stayed there for the rest of his career because, as a serious Roman Catholic, he liked being at a Jesuit institution.

Henry was an enormously curious man. He was fascinated by the family histories of his patients, stimulating him to develop theories of hereditary cancers that were far ahead of their time, when most people believed that cancers were almost always environmental in nature. He worked like Mendel and his peas, observing patterns of inheritance in hundreds of extended families worldwide. Hereditary cancer syndromes, like the ones Dr. Lynch investigated, include gene mutations that predispose some people to more common cancers. One form of hereditary cancer is Lynch Syndrome (also known as hereditary non-polyposis colorectal cancer, or HNPCC) because Dr. Lynch first identified families in which it occurs. People with Lynch syndrome have a higher risk of certain other types of cancer, including endometrial, ovary, stomach, small intestine, hepatobiliary tract, upper urinary tract, brain, and skin. The increased risk for these cancers is due to inherited mutations that impair DNA mismatch repair. Some years ago, I had the chance to talk to Henry about one of my patients who developed her first colon cancer at age 34, and then received adjuvant chemotherapy. She subsequently developed pancreatic cancer and a second colon cancer. Adriana is doing well now, in part because I was able to aggressively surveille her for new primaries based on the principles that Dr. Lynch developed. I am still in contact with her as her mother is being treated for metastatic gastric cancer.

Henry reversed the trend of working from bench to bedside. He was most interested in patients and their histories, rather than treatment or laboratory work. Henry's was a life well-spent, not only for his family and his patients and peers, but also for thousands of people today worldwide who are alive because their cancers were found early based on the principles of cancer genetics he largely developed. His chapter on cancer genetics for the 4th edition of the Oxford Textbook of Oncology is being written by his son, Patrick, who carries on his work at the M.D. Anderson Cancer Center. 


\section{Daniel G. Haller, MD, FACP, FASCO, FRCP}

Gastrointestinal Medical Oncology Professor Emeritus, Abramson Cancer Center at the University of Pennsylvania, Perelman School of Medicine at the University of Pennsylvania, PA, USA. (Email: Daniel.Haller@upbs.upenn.edu) Conflicts of Interest: The author has no conflicts of interest to declare. doi: $10.21037 / \mathrm{cco} .2019 .07 .10$

View this article at: http://dx.doi.org/10.21037/cco.2019.07.10

Cite this article as: Haller DG. In memory of Dr. Henry T. Lynch. Chin Clin Oncol 2019;8(Suppl 1):S28. doi: 10.21037/ cco.2019.07.10 